Acta Agroph., 2019, 26(4), 5-21

doi: $10.31545 /$ aagr/117681

\title{
INFLUENCE OF TOMATO CREAM SOUP PHYSICAL PARAMETERS ON SATIETY POTENTIAL LEVEL*
}

\author{
Magdalena Skotnicka1 ${ }^{1}$, Aneta Ocieczek ${ }^{2}$ (]) \\ ${ }^{1}$ Department of Food Commodity Science, Medical University of Gdansk, Poland \\ ${ }^{2}$ Faculty of Entrepreneurship and Quality Science, Gdynia Maritime University, Poland \\ e-mail: a.ocieczek@wpit.umg.edu.pl
}

\begin{abstract}
This study analysed the diversity of subjectively perceived satiety level induced by the consumption of isocaloric portions of tomato cream soup, prepared with starch additions such as potatoes, pearl barley, pasta and white rice, in the context of differences in weight, viscosity and density of individual tomato cream soups. The study assumed that diversity of physical parameters of soups, determined by the type of the starch addition, affects the feeling of satiety after consumption. Determination of the satiety level after consumption of an isocaloric portion of soup was carried out among 186 persons. For each of the examined soups, weight, viscosity and density of the isocaloric portion was determined. The level of subjectively perceived satiety after consumption of an isocaloric portion of soup was determined using the unstructured visual analogue scale, VAS. The weight of the isocaloric portion was determined by weighing, viscosity was determined using the Brookfield DV-III model viscometer, with the "Rheocalc" software, density was determined using the pycnometer. The highest satiety potential, expressed as the area under the curve (AUC $=(\mathrm{VAS}, \mathrm{t}))$, was found for tomato soup with potato AUC, and the lowest - tomato soup with pasta. The soup with potatoes demonstrated the highest weight, the highest viscosity and the lowest density of an isocaloric portion. The comparison of the parameter values for multiple regression equations, determining the relation between AUC values and the examined physical properties of soups, demonstrated that soups of high weight, significant viscosity and low density of the isocaloric portion show a high ability to induce the feeling of satiety.

Keyw ords: density, viscosity, weight, satiety level
\end{abstract}

\section{INTRODUCTION}

Overweight and obesity are the main threats to public health in Poland and in the world, contributing to the occurrence of such chronic diseases as type 2 diabetes, cardiovascular diseases (cerebral stroke, hypertension), malignant tumours,

* This work was supported by the grant No. WPiT/2019/PZ/05 (Wydział Przedsiębiorczości i Towaroznawstwa)

(C) 2019 Institute of Agrophysics, Polish Academy of Sciences 
gallstones, non-alcoholic hepatic steatosis, hormonal disorders, degenerative changes in the osteoarticular system and sleep apnoea. At the same time, it should be emphasized that the frequency of overweight and obesity shows a growing trend. Therefore, solutions for controlling and hindering the excessive growth of body weight related to accumulation of adipose tissue in the body are being sought. Although educational programmes have been implemented, promoting a healthy and active lifestyle, their efficiency has proved low. However, the results of research demonstrated that following restrictive diets proves in the longer term ineffective, as they require a systematic regime for specific meals and elimination of many food products (Chambers et al. 2015). At the same time, physicians and dieticians advocate the need to apply a rational and balanced diet. Therefore, in view of the growing problem of obesity, a concept emerged to design diets that would take into account not only principles of rational nutrition and proper meal balance, but also ensure a long-term feeling of satiety, which in the light of research on nutritional behaviour might promote desirable effects leading to the body weight loss. Evoking a feeling of early satiation leading to termination of the meal consumption and inducing the feeling of long-term satiety can become a useful tool for controlling the amount of energy provided with food, and consequently, for controlling body weight.

Nutritional behaviours are a complex interaction between hunger, appetite and satiety. Regulation of the consumed food is conditioned by interrelations between of four types of signals integrated with the hunger and satiety centres, located in hypothalamic nuclei. Interaction of motor, metabolic, hormonal and thermal stimuli results in stimulating the satiety or hunger centre. Hunger is conditioned by the physiological need to eat. In turn, appetite is a psychological desire to eat, related to sensual feelings, emotional, social and cultural signals. A state contrary to appetite and hunger is satiety, understood as the feeling of fullness, perceived by the body both physiologically and psychologically, which lingers after the meal and suppresses further activities aimed at taking food in order to provide the body with energy, until the feeling of hunger returns (Anderson 1996). The feeling of satiety after a meal is evoked by various mechanisms, which are initiated one by one, when the food passes through the entire digestive tract. In the first, early phase, the feeling of satiety is affected by the feeling of a reward/pleasure evoked by the type of meal and its sensory values, stimulating senses, such as smell or look of the meal. A significant role is also played by individual cognitive predispositions, which includes prior assumption of food palatability (van Kleef et al. 2012). Another phase includes stimuli evoked by the consumption of food, which includes stomach stretching and activity of the intestine system (Kocełak et al. 2009). At this stage, the volume of the meal plays an important role. Food, moving from the oesophagus to the stomach, causes stretching of its walls and stimulates mechanical and chemical 
receptors, sending signals afterwards to the central nervous system (CNS). The full stomach stimulates the end of the process of further food consumption. However, the composition of food starts to play a crucial role in stimulating the feeling of satiety only in the small intestine, when receptors located in the vagus nerve are stimulated (Phillips and Powley 1996).

The state of satiety is affected not only by the neuro-hormonal hunger regulators, but also by the type of food that reaches the stomach, its chemical composition, method of preparation, weight, volume and a range of other not entirely identified factors.

The application of the satiety potential to estimate the food ability to evoke the feeling of satiety related to its consumption usually involves measurement of the subjective feeling of satiety perceived after the consumption of an isocaloric portion of food. Using the knowledge concerning the satiety potential of food as its new qualitative feature opens broad possibilities for those studies. Food satiety potential, perceived as its ability to evoke the feeling of satiety, can be analysed in various aspects (Skotnicka and Ocieczek 2014). Modification of food satiety potential can be caused by primary differences in the chemical composition of food or its physical properties and by secondary differences, resulting from the effect of technological processes and storage phenomena (Ocieczek and Urban-Rajniak 2018). Therefore, relations between the ability of food to evoke the feeling of satiety and chemical composition of this food, most frequently described in literature, should be considered unsatisfactory for full determination of the satiety potential of individual food products.

Taking up the problem of applying satiety properties to determine food parameters affecting its satiety potential requires an integral approach involving many scientific disciplines related to food.

The aim of the paper was to describe the diversity of a subjectively perceived level of satiety (VAS) induced by the consumption of an isocaloric portion of tomato cream soup, prepared with the use of such additives as potatoes, pearl barley, pasta and white rice, in the aspect of differences in weight, viscosity and density of individual soups. The results obtained made it possible to determine satiety potential (AUC) of the examined soups, which expressed the summary value of changes in subjectively perceived level of satiety in time.

\section{MATERIALS AND METHODS}

\section{Participants}

The study was conducted in 2017 . The study included 186 people living in northern Poland (112 women, 74 men). The criteria for being qualified for the study were as follows: BMI 19.4-24.8 $\mathrm{kg} \mathrm{m}^{-2}$ and age of 20-35 years. The participants in the study were healthy, in good nutritional condition, took no medicines or diet 
supplements and did not apply any special diets. All participants voluntarily signed a consent form for participation in the study, which was approved by the Institutional Ethics Committee at the Medical University of Gdańsk (NKBBN/356/2013). The panellists participating in the study completed a questionnaire with questions concerning the age, body weight, height, pregnancy status, cigarette smoking and physical activity.

\section{Study products}

The research material consisted of four types of tomato cream soup prepared in four variants: with an addition of potatoes, pearl barley, white rice or pasta. Soups were mixed using the laboratory mixer at 21,800 mixing speed (rev. $\min ^{-1}$ ) for 1 minute. Soups were served at a constant temperature of $55^{\circ} \mathrm{C}$. Characteristic features of isocaloric portions are presented in Table 1. Cream type soups were prepared using $250 \mathrm{ml}$ of broth as a base, with an energy value of $42 \mathrm{kcal}(175 \mathrm{~kJ})$, to which starch additions (potatoes, pearl barley, white rice and pasta) were added, to ensure the energy value of a ready-to-eat portion at the level of $150 \mathrm{kcal}(628 \mathrm{~kJ})$. All examined soup samples demonstrated the same calorific value, but differentiated physical properties and various chemical compositions, which was conditioned by the starch addition used.

Table 1. Characteristic features of isocaloric $(150 \mathrm{kcal})$ portions of cream soup with various starch additions

\begin{tabular}{|c|c|c|c|c|c|c|c|}
\hline $\begin{array}{c}\text { Cream soup } \\
\text { with }\end{array}$ & $\begin{array}{l}\text { Energy } \\
\text { value } \\
\text { (kcal) }\end{array}$ & $\begin{array}{c}\text { Soup } \\
\text { weight } \\
\text { (g) }\end{array}$ & $\begin{array}{c}\text { Addition } \\
\text { weight } \\
(\mathrm{g})\end{array}$ & $\begin{array}{l}\text { Protein per } \\
\text { portion } \\
(\mathrm{g})\end{array}$ & $\begin{array}{c}\text { Carbohydrates } \\
\text { per portion } \\
(\mathrm{g})\end{array}$ & $\begin{array}{l}\text { Fat per } \\
\text { portion } \\
(\mathrm{g})\end{array}$ & $\begin{array}{l}\text { Fibre per } \\
\text { portion } \\
(\mathrm{g})\end{array}$ \\
\hline Potatoes & 42 & 374 & 120 & 2.5 & 22.1 & 1.7 & 1.8 \\
\hline Pearl barley & 42 & 326 & 72 & 1.7 & 16.5 & 0.5 & 1.3 \\
\hline White rice & 42 & 341 & 87 & 2.3 & 24.7 & 0.3 & 0.8 \\
\hline Pasta & 42 & 362 & 108 & 3.8 & 23.9 & 0.8 & 0.8 \\
\hline
\end{tabular}

\section{Study design}

This was a crossover, single blind study. Each participant tested four breakfasts on four separate days. The order of the test breakfasts was randomized. The study was carried out in the morning, between $8 \mathrm{AM}$ and $9 \mathrm{AM}$, and the participants were on an empty stomach at the beginning of the study. Each study participant assessed the level of hunger and satiety they felt prior to consuming the product and after consuming it at one hour intervals for the subsequent 120 minutes.

\section{Satiety ratings}

An unstructured $100 \mathrm{~mm}$ visual analogue scale (VAS) with $0 \mathrm{~mm}$ as a "very hungry" end point, and $100 \mathrm{~mm}$ as a "very satiated" end point, was used. Participants consumed the entire sample, and the duration of intake was as short as possible and did not exceed 5 minutes. A serving had a calorific value of $150 \mathrm{kcal}(628 \mathrm{~kJ})$. 
Participants specified the levels on the (VAS) scale for 120 minutes in the morning. The first measurement was carried out on an empty stomach and the next measurement after consuming $150 \mathrm{kcal}$ of portion cream soups. The next measurement was carried out after 30, 60, 90 minutes and the final one after 120 minutes. Each patient tested each type of soup at two day intervals. The mean values of subjectively perceived feeling of satiety (VAS level) were then calculated and presented in the charts as a function of time, which made it possible to estimate the area under the curve (AUC) to quantify the satiety potential of the examined product.

\section{Physicochemical research}

The weight of isocaloric portions of the examined soups was determined by weighting the products. The obtained values were correlated with the estimated AUC results (the area under the curve).

The viscosity of the examined soups was determined using a Brookfield viscometer (model DV-III with a small sample adapter) with "Reocalc" software. Spindles were selected in such a manner as to obtain the same cutting speed. Before determination, samples were thermo-regulated in an incubator for 15 minutes at $55^{\circ} \mathrm{C}$. During the viscosity measurement, the measuring vessel was also thermo-regulated. The measurement was made in isothermal conditions. The obtained viscosity values were correlated with the estimated AUC results (area under the curve).

The density of the examined soups, understood as the quotient of weight and volume, was determined with a pycnometer (Figura and Teixeira 2007). The obtained density values were correlated with the estimated AUC results (area under the curve).

\section{Statistical analysis}

The obtained results were verified statistically with an ANOVA single factor analysis of variance, using STATISTICA 12.0 software. The multiple regression parameters, taking into account the concept of shared variance, were estimated using the REGLINP command in the Excel 2010 PL spreadsheet. In order to determine the levels of satiety and hunger, the area under the curve (AUC) was computed using the trapezoid method. The measurement was carried out every hour for 120 minutes. The correlation of the tested parameters was then calculated in order to determine the general trend and the relationships between the tested parameters. A significance level of $\mathrm{p}<0.05$ was adopted.

\section{RESULTS}

The average satiety level perceived on an empty stomach in the entire population was determined as VAS $=2.2$; $\mathrm{SD}(0.13)$, while the average satiety level felt at fasting by women was determined as slightly higher $(\mathrm{VAS}=2.23$; $\mathrm{SD}(0.16))$ in comparison to the same satiety level determined 
in the male population (VAS $=2.17$; SD $(0.17)$ ). Next, the participants were served an isocaloric portion of soup. The statistical analysis demonstrated that regardless of the type of consumed soup, no statistically significant differences were found $(\mathrm{p}<0.05)$ in the subjective evaluation of the satiety level consumption that would be conditioned by the sex of the study participants. The hypothesis was verified based on the ANOVA test results, which demonstrated that in case of the soup with potatoes $p=0.4976$, the soup with the addition of pearl barley $p=0.4528$, the soup with rice $p=0.4157$ and the soup with the addition of pasta $p=0.4574$. The results of changes in the average level of subjectively perceived satiety at specific time intervals depending on sex are presented in Table 2.

Table 2. The level of soup satiety for an isocaloric $150 \mathrm{kcal}$ portion determined with a VAS (visual analogue scale)

\begin{tabular}{|c|c|c|c|c|c|c|c|}
\hline \multirow{2}{*}{ Type of soup } & \multicolumn{7}{|c|}{ Fasting After intake After 30 min After 60 min After 90 min After 120 min AUC } \\
\hline & & & & Wol & & & \\
\hline potatoes & 2.06 & 9.80 & 9.34 & 8.45 & 8.02 & 7.24 & 200.23 \\
\hline pearl barley & 2.16 & 9.37 & 8.67 & 8.25 & 6.65 & 6.54 & 187.53 \\
\hline $\begin{array}{l}\text { rice } \\
\text { rice }\end{array}$ & 2.43 & 9.56 & 9.04 & 7.33 & 6.12 & 4.32 & 178.34 \\
\hline pasta & 2.3 & 9.65 & 8.87 & $\begin{array}{r}6.87 \\
\mathrm{M}\end{array}$ & 5.53 & 4.35 & 172.24 \\
\hline potatoes & 2.30 & 9.61 & 9.10 & 8.40 & 7.76 & 7.08 & 198.95 \\
\hline pearl barley & 1.97 & 8.91 & 8.56 & 8.14 & 6.44 & 5.94 & 181.01 \\
\hline rice & 2.33 & 9.12 & 8.87 & 7.06 & 5.73 & 4.11 & 171.17 \\
\hline pasta & 2.08 & 9.25 & 8.55 & 6.56 & 5.17 & 3.91 & 163.67 \\
\hline
\end{tabular}

The results indicate a lack of diversity in the level of subjectively perceived satiety conditioned by the sex of the study participants for the consumption of any type of the examined cream soups.

All samples under examination, although characterized by the same energy value, demonstrated a differentiated level of subjectively perceived satiety just after their consumption and during the entire period of the study. Immediately after intake, the highest level of subjectively perceived satiety was recorded for the soup with the addition of potatoes (VAS $=9.7$; SD (0.23)). At the same time, it should be emphasized that it was the largest, in terms of weight, portion among all the soups under analysis $(374 \mathrm{~g})$. The smallest portion in terms of weight was the cream soup with pearl barley $(326 \mathrm{~g})$.

The correlation between the weight of all examined isocaloric portions of soup and the average value of subjectively perceived satiety directly after their intake was evaluated, obtaining a value of Pearson coefficient of 0.7317 . A relatively high value of the coefficient may indicate a significant role of the meal weight for inducing a subjective feeling of satiety directly after a meal. 
In the initial period of the study, which covered determination of subjectively perceived level of satiety evoked by consumption of an isocaloric portion of each of the four types of examined soups, it was found to exceed the value of 9 in the VAS scale, both for women and men. Subsequent measurements made at equal time intervals demonstrated that subjectively perceived level of satiety evoked by the consumption of a specific type of soup was characterized by a varied dynamics of changes conditioned by the type of the starch addition applied, as presented in Figure 1. After 30 minutes following consumption, the level of satiety felt by study participants was reduced in all samples under analysis on average by 0.5 on the VAS scale. Subsequent measurements recorded over time demonstrated that the level of satiety felt by the participants after the consumption of tomato soup with rice $\mathrm{VAS}_{120 \mathrm{~min}}=4.22$ and pasta $\mathrm{VAS}_{120 \mathrm{~min}}=4.13$ was reduced at the fastest rate. The best satiety properties were attributed to the soup with the addition of potatoes $\operatorname{VAS}_{120 \mathrm{~min}}=7.16$.

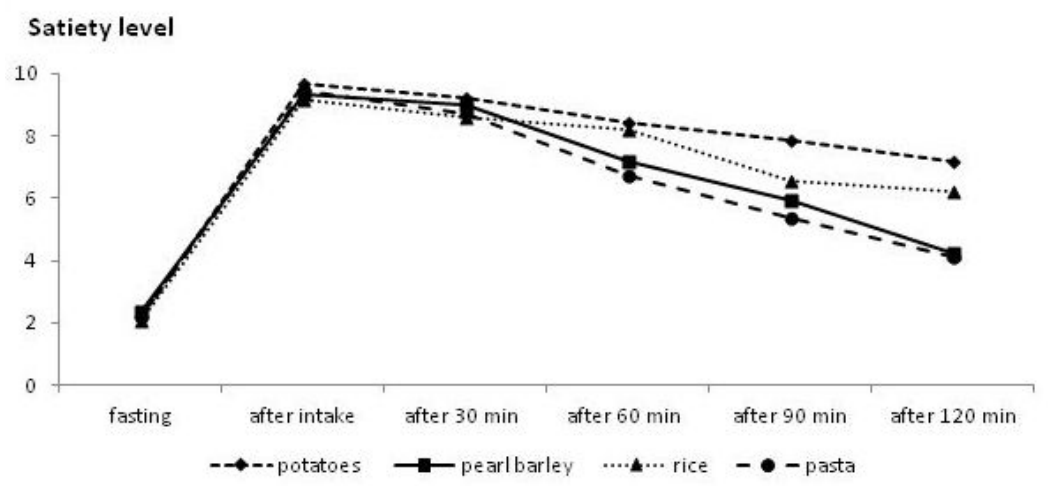

Fig. 1. Determined satiety level after the consumption of cream soups depending on the addition used.

The statistical analysis of the obtained results carried out with the ANOVA test demonstrated that subjectively perceived satiety level was determined by the type of soup addition. In the statistical evaluation, the level of satiety was assumed as a dependent variable. It was calculated that the type of soup had a significant effect on shaping the level of satiety related to its consumption $(\mathrm{F}=6.27 ; \mathrm{p}=0.002 ; \alpha=0.05)$.

In order to generalize partial values, describing mean values expressed on the VAS scale reflecting changes in the subjectively perceived satiety level in the function of time, values of the area under curve (AUC) were determined for quantifying the satiety potential of the examined types of soup. A comparison of the obtained results led to the conclusion that the lowest satiety potential was characteristic for the soup with wheat pasta $(\mathrm{AUC}=168.05)$ and the soup with the addition of white rice (AUC =175.04). At the same time, it should be emphasized that the lowest mean value of subjectively 
felt satiety in the initial phase of the study was found for the soup with the addition of pearl barley (VAS $=9.37$ ), which was relatively slightly reduced during the experiment (VAS $=6.24$ ). In turn, the total value expressing the satiety potential and described with the AUC value for this soup amounted to 184.26 , which was a slightly lower result than the soup with the addition of potatoes, described as the most filling $(\mathrm{AUC}=200.64)$.

Additionally, the correlation between the weight of all examined isocaloric soup portions and the AUC value (describing their satiety potential) was evaluated, obtaining the value of Pearson coefficient of 0.4485 . A relatively low value of the coefficient may indicate the lack of a significant role of the meal weight in inducing a feeling of long-term satiety.

In examining other physical properties of soups, it was found that despite applying the same mixing force and time for preparing the examined soup samples, individual soups differed in texture, described by the measurement of their viscosity and density. The soup prepared with the addition of pearl barley least resembled smooth cream.

Determination of the viscosity of the examined cream soups was made after heating them up to $55^{\circ} \mathrm{C}$.

Table 3. Results of cream soup viscosity determination with a Brookfield viscometer

\begin{tabular}{lcccc}
\hline $\begin{array}{c}\text { Cream soup } \\
\text { with addition of }\end{array}$ & $\begin{array}{c}\text { Shear rate } \\
\left(1 \mathrm{~s} \mathrm{~s}^{-1}\right)\end{array}$ & $\begin{array}{c}\text { Temperature } \\
\left({ }^{\circ} \mathrm{C}\right)\end{array}$ & $\begin{array}{c}\text { Viscosity } \\
(\mathrm{mPa} \mathrm{s})\end{array}$ & $\begin{array}{c}\text { Standard deviation } \\
\text { SD }\end{array}$ \\
\hline Potatoes & 55 & 55 & 298 & 6.7 \\
Pearl barley & 55 & 55 & 102 & 2.4 \\
White rice & 55 & 55 & 249 & 6.3 \\
Pasta & 55 & 55 & 251 & 5.5 \\
\hline
\end{tabular}

The results indicate that the examined soups differed in viscosity. The highest viscosity was identified for the soup with the addition of potatoes $(298 \mathrm{mPa} \mathrm{s})$ and the lowest was for the soup with pearl barley $(102 \mathrm{mPa} \mathrm{s})$. In evaluating the correlation between the viscosity of specific isocaloric soup portions and the average value of subjectively perceived satiety directly after consumption, it was found that the value of Pearson coefficient was 0.3336 . A relatively low value of this coefficient may indicate an insignificant role of the meal viscosity in affecting the subjective feeling of satiety immediately after the meal. In turn, evaluating the correlation between the viscosity of the examined soups and the value of AUC, a Pearson coefficient value of 0.5341 was found, which may indicate a higher effect of meal viscosity on inducing a feeling of long-term satiety.

The density of the examined cream type soups was also determined after heating them up to $55^{\circ} \mathrm{C}$. The reason was that many substances are subject to thermal expansion after heating, which means that they increase their volume without any change in their weight. 
Table 4. Results of cream soup density determination using a pycnometer

\begin{tabular}{lccc}
\hline $\begin{array}{c}\text { Cream soup } \\
\text { with addition of }\end{array}$ & $\begin{array}{c}\text { Temperature } \\
\left({ }^{\circ} \mathrm{C}\right)\end{array}$ & $\begin{array}{c}\text { Density } \\
\left(\mathrm{g} \mathrm{cm}^{-3}\right)\end{array}$ & $\begin{array}{c}\text { Standard deviation } \\
\text { SD }\end{array}$ \\
\hline Potatoes & 55 & 0.963 & 0.004 \\
Pearl barley & 55 & 0.980 & 0.016 \\
White rice & 55 & 0.993 & 0.003 \\
Pasta & 55 & 1.017 & 0.008 \\
\hline
\end{tabular}

The results suggest that the examined soups also differed in their density. The soup with the addition of pasta demonstrated the highest density $\left(1.017 \mathrm{~g} \mathrm{~cm}^{-3}\right)$, and the lowest was the soup with the addition of potatoes $\left(0.963 \mathrm{~g} \mathrm{~cm}^{-3}\right)$. In evaluating the correlation between the density of individual isocaloric soup portions and the average value of subjectively perceived satiety directly after consumption, it was found that the value of the Pearson coefficient was 0.3564 . A relatively low and negative value of this coefficient allows us to assume that there is no significant effect of soup density on its ability to evoke a subjectively perceived feeling of satiety immediately after the meal. In turn, in evaluating the correlation between the density of examined soups and the AUC value, the value of the Pearson coefficient found was -0.8230 , which indicates a significant effect of meal density on inducing a long-term feeling of satiety. At the same time, it should be emphasized that the correlation is negative, which shows that an isocaloric soup portion revealing a high satiety potential should be characterized by a large weight, related to the presence of water, with significant volume at the same time. The joint existence of those two properties in the product intended for consumption may ensure a relatively fast occurrence of early satiation and promote long-term satiety.

The estimated values of Pearson correlation coefficients between the ability to evoke subjectively perceived feeling of satiety immediately after the meal and the satiety potential and values of individual physical parameters differentiating the soups under examination, suggest that the highest $(\mathrm{r}=-0.8230)$ correlation dependency was found for the satiety potential value (AUC) and soup density.

The final element of the research conducted was an attempt to determine the direction and the strength of the effect of three physical parameters (weight, viscosity and density) of physical parameters of cream soups in determining their satiety potential (AUC). The results of empirical measurements of AUC values became the basis for evaluating the relations between three selected physical parameters of soups and subjectively perceived satiety potential of the examined cream soups, as the summary resultant of all parameters. Based on the obtained results, multiple regression analysis was carried out, aiming at minimizing the sum of squared deviation. The value of the area under curve (AUC) was assumed as a dependent variable, while the input independent variables were: weight (M), viscosity (L) and density $(\mathrm{G})$. Physical parameters of cream soups, arbitrarily assumed for the 
purpose of this study and reduced to critical parameters during the analytical proceedings, were independent variables. Estimation of the significance of variables was determined at the level of $\mathrm{p} \leq 0.05$.

$$
\begin{array}{ll}
\text { AUC }=-457 \cdot \mathrm{G}+0.1251 \cdot \mathrm{L}-0.2170 \cdot \mathrm{M}+684 & \mathrm{R}^{2}=0.2872 \\
\text { AUC }=0.0879 \cdot \mathrm{L}-0.0520 \cdot \mathrm{M}+183 & \mathrm{R}^{2}=0.2872 \\
\text { AUC }=-425 \cdot \mathrm{G}+0.2224 \cdot \mathrm{M}+527 & \mathrm{R}^{2}=0.8294 \\
\text { AUC }=-441 \cdot \mathrm{G}+0.077 \cdot \mathrm{L}+604 & \mathrm{R}^{2}=0.9677
\end{array}
$$

An analysis of equations indicated that the viscosity has a clearly positive effect on the value of satiety potential of soups, while their density has a negative effect. At the same time, it can be observed that the density is much more important in promoting the feeling of long-term satiety than viscosity of soups. A soup promoting the feeling of long-term satiety should be characterized by low density, which may be obtained by trying to increase its volume while preserving its weight. This, in turn, can be obtained by applying such components that significantly increase their volume under the effect of water. An example of such a type of component is food fibre.

\section{DISCUSSION}

The discussion on the effect of individual food components and its physical properties on evoking of the feeling of satiety has been going on for many years. Many authors emphasize that a significant effect on the feeling of satiety is evoked by protein intake (Halton and $\mathrm{Hu}$ 2004, Paddon-Jones et al. 2008), and in particular, animal protein (Lejeune et al. 2005). However, based on the results of conducted studies, it can be assumed that an equally important component determining the satiety potential of cream soups is the amount and the type of carbohydrates they contain. The role of carbohydrates in regulating the feeling of satiety has also been the subject of various studies and extreme opinions, as reported by Geliebter et al. (2015). On one hand, monosaccharides have a strong effect on sensory-specific satiety, also due to hedonistic impact of sweetness (Hammersley et al. 2007). However, what is most important from the perspective of satiety potential of food is the consumption of complex carbohydrates, particularly starch (Aller et al. 2011).

In our study, all soups were prepared based on the same broth, which was enriched with a starch addition of varied weight, depending on the energy value of this addition, and at the same time, of a diversified specificity conditioned by the type of this addition (different types of starch). Thus, it was assumed that the share of a starch addition would be a significant factor determining the satiety potential of examined cream soups. The effect of the share of various types of starch in food products on inducing the feeling of satiety related to their consumption has been examined many times, but the results of those studies did not make it possible to formulate clear conclusions. According to Alviña et al. (2000), the consumption of 
meals, in particular soups, with an addition of starch can significantly help to reduce body weight by evoking the feeling of long-term satiety. However, the results of studies by Souza da Silva et al. (2014) did not clearly confirm this thesis.

Among food components, the highest importance in inducing the feeling of satiety is attributed to dietary fibre. Water soluble fractions of dietary fibre that due to their significant hydration result in an increase in food viscosity, which contributes to a slower emptying of the stomach (Benelam 2009), deserve particular attention. Water-soluble dietary fibre (SDF) significantly expands in stomach, enforcing the feeling of fullness (Lattimer and Haub 2010, Yuan et al. 2014). Additionally, the presence of water insoluble dietary fibre, e.g. resistant starch making up part of this fraction, in food increases the time needed for chewing and swallowing such food. Due to this mechanism, signals, after the state of satiety is reached, successfully reach the hunger and satiety centre located in hypothalamic nuclei, and consequently, we terminate the meal in a relatively short time. The intake of fibre helps to reduce appetite (Slavin and Green 2007, Harrold et al. 2014). The role of dietary fibre in maintaining proper body weight has been analysed in many aspects. The role of fibre was examined as a factor helping to improve the dynamics of the defecation process and reducing the risk of many diseases. The interest in fibre as a component of food products demonstrating high satiety potential has emerged relatively recently. In the current study, the highest content of dietary fibre was found in tomato soup with the addition of potato and pearl barley. Those two types of soups were characterized by the highest satiety potential, which can indicate the existence of a positive relationship between the content of dietary fibre and satiety potential of food rich in this component. Similar conclusions were reached by Savastano et al. (2014) and Ye et al. (2015), who proved that an addition of dietary fibre to food significantly increased the feeling of satiety and reduced appetite after its consumption. In turn, Bajerska et al. (2016) examined the effect of adding sour cherry pomace $(\mathrm{CP})$, the by-product obtained during fruit processing, to the production of muffins to replace wheat flour, applying it in different shares. It was observed that enrichment of the baking mix with 20 and $30 \%$ share of CP increased the satiety potential of those products and created a lower supply of energy related to their consumption. Lyly et al. (2009) recorded benefits related to the measurement of the feeling of satiety in a study consisting in providing study participants with beverages enriched with various types of dietary fibre and comparing them with beverages which did not contain any fibre. The role of fibre in affecting satiety potential of food was also for bread (Ocieczek and Urban-Rajniak 2018). The researchers found higher satiety potential in fibre-enriched bread or in stale bread, naturally rich in resistant starch, produced as a result of retrogradation. 
The role of dietary fibre in regulating food intake becomes particularly clear when the dietary fibre occurs in food products of high water content. For this reason, the consumption of cream soups is recommended as a good way to satisfy hunger efficiently and effectively. The results of our studies confirm this thesis, since regardless of the type of the starch addition applied, all soups were characterized by a relatively high level of subjectively perceived satiety directly after intake and after 120 minutes of the study. The obtained results may indicate that the carbohydrates represented by starch and fiber were a factor significantly affecting the satiety potential of the soups studied. The presence of these fractions determines the viscosity of the soup due to their swelling and gel formation. Therefore, it can be assumed that a good indicator of the satiety potential of soups can be a multiplier of carbohydrate and fiber.

The effect of water in evoking the feeling of satiety, particularly in the first phase after consuming a food portion, can be explained by the fact that a high share of water in food increases its volume and weight. This, in turn, contributes to inducing the feeling of satiety, since the volume of food is a key element of regulation of food intake prior to absorption.

The subjectively perceived level of satiety after food consumption is affected not only by phenomena related to hormonal regulation of satiety, but also the type of food consumed, time of consumption, serving methods and the circumstances of consumption. Herman et al. (2015) described in detail the portion-size effect mechanism, PSE), which is responsible for the size of the meal consumed. According to this theory, when served a larger portion, we consume more food. However, the results of previous studies carried out by Marchiory et al. (2014) did not lead to the formulation of an explicit thesis identifying the factor making us eat more when serving larger portions. Hunger is probably affected both by sensory and cognitive factors, described by Bellisle and Blundell (2013). The colour and the temperature of served food is also important, as reported by Suzuki et al. (2017). In their research, soups with an addition of white, yellow and blue die were analysed. It was found that the consumption of an isocaloric blue-died soup evoked the lowest feeling of satiety compared to two others. The results of this study show that colour of food is important in affecting a subjective evaluation of satiety evoked by its consumption. In the current study, soups after mixing had a similar orange colour, which reduced the factors that might potentially disturb the research model due to the appearance of tested portions.

Inducing the feeling of satiety related to the consumption of food is based on complex interactions of various parameters characterizing food, such as its energy potential (amount of calories), weight, volume, sensory properties, meal temperature and the so-called "food topography", which is determined by the size of bites, frequency of biting and swallowing rate (de Graaf 2012). Nguyen et al. (2017) 
confirmed the results of previous research, proving a favourable effect of food volume on evoking the feeling of satiety. They found that this is a feature definitely more important than energy value. In the current study, a critical factor in determining the feeling of satiety turned out to be density, which was inversely proportional to the average, subjectively perceived feeling of satiety related to the consumption of an isocaloric portion of soup. Following the definition of density, it should be described as the weight to volume ratio. This means that increasing the volume and preserving the same weight will result in density reduction. Therefore, when designing food satiating properties, attention should be paid to such its components as dietary fibre, which is characterized by a favourable set of properties promoting the production of food with high satiety potential. Those properties include low energy value, ability to increase volume in the presence of water, ability to create viscous texture under the effect of water and the need to bite during its consumption.

To sum up, it should be claimed that apart from chemical composition, affecting the nutritional value of food, a highly important role is played by its physical features, such as texture and ability to increase the volume as a result of expansion. To date, a limited number of papers concerning this issue have been published. There are certain data indicating that the factors affecting the satiety potential of food should include the degree of its disintegration and its viscosity (Mattes and Rothacker 2001). According to Mattes (2005), products of a high degree of disintegration evoke the feeling of satiety at a faster rate, and at the same time this feeling is maintained for longer, assuming the consumption of a portion of the same energy value in relation to non-mixed product. Already the results of studies conducted in 1984 by Kissileff et al. suggested that soups were more satiating than other types of food. This is not only due to their chemical properties, but also to physical properties. Similar conclusions were reached by Flood and Rolls (2007). Those researchers analysed vegetable soups with butter, and the obtained results suggested that consumption of soups with various degrees of disintegration could differentiate energy value of a subsequent meal even in the $20 \%$ range. The obtained results confirm the assumptions of the favourable effect of strong disintegration of components in the examined soups for better use of the starch it contained, regardless of its origin (potatoes or groats). Therefore, it can be claimed that the consumption of cream soups favours faster emergence of the feeling of satiety, which was confirmed in the current study. The existence of such a relationship was also indicated in the results of studies by other authors (Tang et al. 2016). They claim that viscous and homogenous products are the best to satiate an appetite. This is related to reduced chewing in mouth, and the shorter time that food stays in the oral cavity, which leads to reduced intake. In turn, Pentikainen et al. (2017) conducted research on the effect of various types of barley bread of various rheological features on its satiety potential. The results of the research indicated the existence of a relationship between the 
physical properties of food and achieved state of satiety. Products that were heavy, hard and served in large-pieces better satiated the body. The authors suggested that modification of the product form and structure could encourage increased processing in mouth, which can help in effective management of food consumption. Similar results were obtained by Dhillon et al. (2016), who demonstrated that the physical form of food is of high importance for nutritional and health-promoting behaviours, and it should not be omitted while interpreting factors determining the satiety potential of each type of food.

The process of reaching satiety is highly complex with many factors affecting the satiety potential of food. Texture, as a result of many physical properties of food, plays a crucial role in developing a food's ability to evoke the feeling of satiety related to its intake, and therefore, the amount of consumed food (McCrickerd et al. 2014). For food products characterized by a high viscosity, it can significantly affect the satiating properties of food. According to Zijlstra et al. (2008), food products of various viscosity but the same palatability, nutritional value and energy density evoke the feeling of satiety of various degree of intensity compared to products with a significantly lower viscosity. At the same time, if it is possible to consume a portion of food without caloric limitations, we will eat less amounts of mixed products than products in a solid form or in large bites (Chambers et al. 2015). However, it should be emphasized that the role of viscosity in affecting satiating properties of food is only limited to fragmented or mushy products and beverages.

The results of numerous studies demonstrate the complexity of the issue concerning satiating properties of food and the number of parameters that can affect it. In view of the complexity of processes occurring in the human body affecting the emergence of the feeling of satiety after food intake, newer and better methods to measure chemical and physical properties of food and to precisely determine their effect on the feeling of satiety are being constantly sought (Campbell et al. 2017). Consequently, it can be assumed that in future it will be possible to design food products of highly-satiating properties, by applying knowledge of food chemistry and rheology.

\section{CONCLUSIONS}

1. Mixed products of high homogeneity, such as cream soups, are products with high satiating properties.

2. Tomato soup with the addition of potatoes demonstrated the highest value of satiety potential.

3. Tomato soup with the addition of potatoes demonstrated the highest weight and viscosity and the lowest density.

4. A high weight and viscosity, and a low density of a cream soup promote induction of the feeling of satiety both directly after consumption and as long-term satiety. 


\section{Conflict of interest: The Authors declare no conflict of interest.}

\section{REFERENCES}

Aller E.E.J.G., Abete I., Astrup A., Martinez J.A., van Baak M.A., 2011. Starches, Sugars and Obesity. Nutrients, 3(3), 341-369, https://doi.org/10.3390/nu3030341

Alviña M., Araya H., Vera G., Pak N., 2000. Effect of starch intake on satiation and satiety in preschool children. Nutr. Res., 20(4), 479-489, https://doi.org/10.1016/S0271-5317(00)00140-8

Anderson G.H., 1996. Hunger, appetite, and food intake. Present Knowledge in Nutrition, 13-17.

Bajerska J., Mildner-Szkudlarz S., Górnaś P., Seglina D., 2016. The effects of muffins enriched with sour cherry pomace on acceptability, glycemic response, satiety and energy intake: a randomized crossover trial. J. Sci. Food Agric., 96(7), 2486-2493, https://doi.org/10.1002/jsfa.7369

Bellisle F., Blundell J.E., 2013.1 - Satiation, satiety: concepts and organisation of behaviour. 2013, in: Satiation, Satiety and the Control of Food Intake. Theory and practice. Woodhead Publ. Series Food Sci., Technol. and Nutr., 3-11, https://doi.org/10.1533/9780857098719.1.3

Benelam B., 2009. Satiation, satiety and their effects on eating behaviour. Nutr. Bull., 34(2), 126-173, https://doi.org/10.1111/j.1467-3010.2009.01753.x

Campbell C.L., Wagoner T.B., Foegeding E.A., 2017. Designing foods for satiety: The roles of food structure and oral processing in satiation and satiety. Food Struc., 13, 1-12, https://doi. org/10.1016/j.foostr.2016.08.002

Chambers L., McCrickerd K., Yeomans M.R., 2015. Optimising foods for satiety. Trends in Food Sci. Technol., 41(2), 149-160, https://doi.org/10.1016/j.tifs.2014.10.007

de Graaf C., 2012. Texture and satiation: The role of oro-sensory exposure time. Physiol. Behav., 107(4), 496-501, https://doi.org/10.1016/j.physbeh.2012.05.008

Dhillon J., Running C.A., Tucker R.M., Mattes R.D., 2016. Effects of food form on appetite and energy balance. Food Qual. Pref., 48, 368-375, https://doi.org/10.1016/J.FOODQUAL.2015.03.009

Figura L.O., Teixeira A.A., 2007. Food physics. Physical Properties - Measurement and Applications. Springer-Verlag Berlin-Heidelberg, pp.

Flood J.E., Rolls B.J., 2007. Soup preloads in a variety of forms reduce meal energy intake. Appet., 49(3), 626-634, https://doi.org/10.1016/j.appet.2007.04.002

Geliebter A., Grillot C.L., Aviram-Friedman R., Haq S., Yahav E., Hashim S.A., 2015. Effects of oatmeal and corn flakes cereal breakfasts on satiety, gastric emptying, glucose, and appetite-related hormones. Ann. Nutr. Metab., 66(2-3), 93-103, https://doi.org/10.1159/000365933

Halton T.L., Hu F.B., 2004. The Effects of High Protein Diets on Thermogenesis, Satiety and Weight Loss: A Critical Review. J. Am. Coll. Nutr., 23(5), 373-385, https://doi.org/10.1080/07315724. 2004.10719381

Hammersley R., Reid M., Duffy M., 2007. How may refined carbohydrates affect satiety and mood? Nutr. Bull., 32(s1), 61-70, https://doi.org/10.1111/j.1467-3010.2007.00605.x

Harrold J., Breslin L., Walsh J., Halford J., Pelkman C., 2014. Satiety effects of a whole-grain fibre composite ingredient: reduced food intake and appetite ratings. Food Func., 5(10), 2574-81, https://doi.org/10.1039/c4fo00253a

Herman P.C., Polivy J., Pliner P., Vartanian L.R., 2015. Mechanisms underlying the portion-size effect. Physiol. Behav., 144, 129-136, https://doi.org/10.1016/j.physbeh.2015.03.025

Kissileff H.R., Gruss L.P., Thornton J., Jordan H.A., 1984. The satiating efficiency of foods. Physiol. Behav., 32(2), 319-332, https://doi.org/10.1016/0031-9384(84)90147-1

Kocełak P., Zahorska-Markiewicz B., Olszanecka-Glinianowicz M., 2009. Hormonal regulation of feeding (in Polish). Endokrynol. Pol., 60(4), 296-301. 
Lattimer J.M., Haub M.D., 2010. Effects of dietary fiber and its components on metabolic health. Nutrients, 2(12), 1266-89, https://doi.org/10.3390/nu2121266

Lejeune M.P.G.M., Kovacs E.M.R., Westerterp-Plantenga M.S., 2005. Additional protein intake limits weight regain after weight loss in humans. BJN, 93(2), 281-9. Retrieved from http://www. ncbi.nlm.nih.gov/pubmed/15788122

Lyly M., Liukkonen K-H., Salmenkallio-Marttila M., Karhunen L., Poutanen K., Lähteenmäki L., 2009. Fibre in beverages can enhance perceived satiety. Eur. J. Nutr., 48(4), 251-258, https://doi. org/10.1007/s00394-009-0009-y

Marchiori D., Papies E.K., Klein O., 2014. The portion size effect on food intake. An anchoring and adjustment process? Appet., 81, 108-115, https://doi.org/10.1016/j.appet.2014.06.018

Mattes R., 2005. Soup and satiety. Physiol.Behav., 83(5), 739-747, https://doi.org/10.1016/j. physbeh.2004.09.021

Mattes R.D., Rothacker D., 2001. Beverage viscosity is inversely related to postprandial hunger in humans. Physiol. Behav., 74(4-5), 551-557, https://doi.org/10.1016/S0031-9384(01)00597-2

McCrickerd K., Chambers L., Yeomans M.R., 2014. Fluid or fuel? The context of consuming a beverage is important for satiety. Plos One, 9(6), 1-10 https://doi.org/10.1371/journal.pone.0100406

Nguyen Q.C., Wahlgren M.B., Almli V.L., Varela P., 2017. Understanding the role of dynamic texture perception in consumers' expectations of satiety and satiation. A case study on barley bread. Food Qual. Pref., 62, 218-226, https://doi.org/10.1016/j.foodqual.2017.06.006

Ocieczek A., Urban-Rajniak A., 2018. Comparison of the satiating potential of selected types of bread. In: Agriculture of the 21st century - problems and challenges (Ed. D. Luczycka) (in Polish), Wyd. Idea Knowledgr Future, Wrocław, pp. 552-562.

Paddon-Jones D., Westman E., Mattes R.D., Wolfe R.R., Astrup A., Westerterp-Plantenga M., 2008. Protein, weight management, and satiety. Am. J. Clin. Nutr., 87(5), 1558S-1561S. Retrieved from http://www.ncbi.nlm.nih.gov/pubmed/18469287

Pentikäinen S., Sozer N., Närväinen J., Sipilä K., Alam S.A., Heiniö R.L., Kolehmainen M., 2017. Do rye product structure, product perceptions and oral processing modulate satiety? Food Qual. Pref., 60, 178-187, https://doi.org/10.1016/j.foodqual.2017.04.011

Phillips R.J., Powley T.L., 1996. Gastric volume rather than nutrient content inhibits food intake. Am. J. Physiol. Regul. I., 271(3), R766-R769, https://doi.org/10.1152/ajpregu.1996.271.3.R766

Savastano D.M., Hodge R.J., Nunez D.J., Walker A., Kapikian R., 2014. Effect of two dietary fibers on satiety and glycemic parameters: a randomized, double-blind, placebo-controlled, exploratory study. Nutr. J., 13(1), 45, https://doi.org/10.1186/1475-2891-13-45

Skotnicka M., Ocieczek A., 2014. Satiety index and food ingredients assessment for selected food products (in Poilsh). Bromat. Chem. Toksykol., 47(3), 716-720.

Slavin J., Green H., 2007. Dietary fibre and satiety. Nutr. Bull., 32(1), 32-42. Retrieved from http:// onlinelibrary.wiley.com/doi/10.1111/j.1467-3010.2007.00603.x/full

Souza da Silva C., Haenen D., Koopmans S.J., Hooiveld G.J.E.J., Bosch G., Bolhuis J E., Gerrits W.J.J., 2014. Effects of resistant starch on behaviour, satiety-related hormones and metabolites in growing pigs. Animal, 8(09), 1402-1411, https://doi.org/10.1017/S1751731114001116

Suzuki M., Kimura R., Kido Y., Inoue T., Moritani T., Nagai N., 2017. Color of hot soup modulates postprandial satiety, thermal sensation, and body temperature in young women. Appet., 114, 209216, https://doi.org/10.1016/j.appet.2017.03.041

Tang J., Larsen D.S., Ferguson L.R., James B.J., 2016. The effect of textural complexity of solid foods on satiation. Physiol. Behav., 163, 17-24, https://doi.org/10.1016/j.physbeh.2016.04.042 
van Kleef E., van Trijp J.C.M., van den Borne J.J.G.C., Zondervan C., 2012. Successful development of satiety enhancing food products: Towards a Multidisciplinary Agenda of Research Challenges. Crit. Rev. Food Sci. Nutr., 52(7), 611-628, https://doi.org/10.1080/10408398.2010.504901

Ye Z., Arumugam V., Haugabrooks E., Williamson P., Hendrich S., 2015. Soluble dietary fiber (Fibersol-2) decreased hunger and increased satiety hormones in humans when ingested with a meal. Nutr. Res., 35(5), 393-400, https://doi.org/10.1016/J.NUTRES.2015.03.004

Yuan J.Y.F., Smeele R.J.M., Harington K.D., van Loon F.M., Wanders A.J., Venn B.J., 2014. The effects of functional fiber on postprandial glycemia, energy intake, satiety, palatability and gastrointestinal wellbeing: a randomized crossover trial. Nutr. J., 13(1), 76, https://doi.org/ 10.1186/1475-2891-13-76

Zijlstra N., Mars M., de Wijk R.A., Westerterp-Plantenga M.S., de Graaf C., 2008. The effect of viscosity on ad libitum food intake. Intern. J. Obesity, 32(4), 676-683, https://doi.org/10.1038/ sj.ijo.0803776 